\section{A utilização do "fluxograma analisador" para a organização da assistência à saúde no Programa Saúde da Família}

\author{
The use of an analytic flowchart to organize \\ healthcare in the Brazilian Family Health Program
}

Tatiane Aparecida Venâncio Barboza ${ }^{1}$ Lislaine Aparecida Fracolli 1

\title{
Introdução
}

1 Escola de Enfermagem, Universidade de São Paulo, São Paulo, Brasil.

Correspondência L. A. Fracolli Escola de Enfermagem, Universidade de São Paulo. Av. Dr. Eneas de Carvalho Aguiar 419, 2 a andar, São Paulo, SP 05403-000, Brasil. lislaine@usp.br

\begin{abstract}
To reorganize healthcare in the Family Health Program (FHP) it is necessary to change the work process in health services. The work process is both the focus of special attention for introducing changes in health services and an important health services management issue. This study aimed to discuss and analyze the use of an analytic flowchart with FHP professionals in São Paulo, Brazil, as an instrument to facilitate selfanalysis of the work process. Data were obtained through focus groups and analyzed using a technique called collective subject discussion. The results showed that the analytic flowchart is a powerful instrument impacting the private exercises of health professionals, making them more controlled and thereby producing services less focused on the physician-centered logic; it can also help solve disputes among different health professionals.
\end{abstract}

Family Health Program; Delivery of Health Care; Health Personnel
Em 1994, o Ministério da Saúde propôs a estratégia do Programa Saúde da Família (PSF), como uma forma de reorganização da produção de cuidados de saúde. O desenvolvimento dessa estratégia tinha como objetivo reorganizar a prática assistencial de saúde sob novas bases e critérios, em substituição ao modelo tradicional de assistência, que é orientado para a cura de doenças e centrado no hospital 1. A estratégia do PSF pressupunha que a atenção à saúde poderia estar centrada na família, a qual deveria ser entendida e percebida a partir de seu ambiente físico e social. Para a estratégia do PSF, a adoção desses pressupostos possibilitaria aos profissionais de saúde uma compreensão ampliada do processo saúde-doença e da necessidade de intervenções que vão além de práticas curativas. O PSF elegeu como diretrizes operacionais os princípios de: caráter substitutivo de suas práticas (dado pela substituição das práticas convencionais de assistência por um novo processo de trabalho, centrado na vigilância à saúde); integralidade e hierarquização das ações (entendendo que a unidade de saúde da família está inserida no primeiro nível de ações e serviços do sistema local de saúde); territorialização e adscrição de clientela (buscando trabalhar com território definido); adoção do trabalho em equipe multiprofissional (a unidade produtiva do PSF é a equipe de saúde da famí- 
lia, a qual é composta minimamente por um médico generalista, um enfermeiro, um auxiliar de enfermagem e de quatro a seis agentes comunitários de saúde) 1 .

A análise dos princípios do PSF revela que embora sua concepção teórica se baseie na tradição herdada da vigilância à saúde, a mudança do modelo assistencial somente ocorrerá a partir da reorganização do processo de trabalho em saúde. E para atingir a dinâmica médico-centrada que opera no caso da saúde, é preciso que se reorganize o trabalho das equipes, atuando nos seus processos decisórios, o que ocorre no ato mesmo da produção de saúde. Esses "novos" fazeres e práticas necessitam tornarem-se concretos e materializarem-se como "tecnologias de trabalho", usadas para produzir saúde.

Segundo Merhy 2, os processos de trabalho concretos, vivenciados nos serviços de saúde, são focos de atenção especial para os processos de gestão da mudança. Para esse autor, existem "efeitos" do processo de trabalho, que se expressam no dia-a-dia dos serviços e, que devem ser "olhados" como lugares estratégicosalvo para operações, que podem disparar potencializações vitais, na direção de novos processos de produção de saúde.

Por se constituir em uma estratégia governamental para reorganização da assistência à saúde, o PSF vem sendo amplamente implantado nos municípios brasileiros, os quais recebem inclusive verbas diferenciadas para o desenvolvimento do programa. No Município de São Paulo, o PSF se instalou a partir do ano de 1998, sob a coordenação da Fundação Zerbini, em parceria com Secretaria Estadual de Saúde, e foi denominado de Projeto QUALIS; tinha como objetivo reorganizar o modelo tecno-assistencial, baseado na promoção, proteção, diagnóstico precoce, tratamento e recuperação de saúde conforme as diretrizes do Sistema Único de Saúde (SUS) ${ }^{3}$. Atualmente, o PSF no Município de São Paulo deixou de ser uma iniciativa do Projeto QUALIS e passou a integrar a proposta política da Secretaria Municipal de Saúde, que de 2000 até hoje, já implantou mais de 600 equipes de saúde da família nas regiões mais carentes do município 3 .

Em São Paulo, o PSF representa uma estratégia de adequação e reorientação da atenção básica e dos demais níveis do sistema. As unidades de saúde da família atuam por intermédio do trabalho de cinco ou seis equipes de saúde. As equipes são compostas por médico (um), enfermeira (uma), auxiliar de enfermagem (dois) e agentes comunitários de saúde (cinco ou seis), e em algumas unidades de saúde da família há odontólogos, psicólogos e nutricionistas incorporados às mesmas. As equipes de PSF, no município, trabalham com cerca de 800 a 1.000 famílias (mais ou menos 4 mil pessoas) e são responsáveis por: cadastrar as famílias; fazer vigilância de saúde pública (sanitária e epidemiológica); conhecer a realidade das famílias sob sua responsabilidade; elaborar um plano de enfrentamento dos determinantes do processo saúde-doença; prestar assistência integral na recuperação da saúde, na prevenção das doenças, na promoção da saúde e na reabilitação; realizar consulta médica, consulta de enfermagem, acolhimento à demanda espontânea, grupos programáticos, atividades lúdicas e de exercício físico e visitas domiciliárias 3 .

Embora o PSF se constitua em uma iniciativa de mudança da saúde, algumas críticas têm sido elaboradas sobre sua real capacidade de fornecer atenção integral, oportuna, contínua, de qualidade e com humanização do atendimento. A análise do PSF/QUALIS na região norte do Município de São Paulo, identificou que a ênfase da produção das unidades de saúde da família estava centrada na recuperação e na cura, viabilizada pela assistência prestada pelas equipes por meio, principalmente, da consulta médica e de enfermagem e associada a uma forte tendência ao pronto atendimento (Salum MJL, comunicação pessoal).

O PSF, como uma estratégia de implantação do SUS, por estar “em realização” e por apresentar uma organização do trabalho em bases não tradicionais, pode ser gerencialmente instrumentalizada para organizar sua produção de cuidados, de forma usuário centrada e com processos de trabalho mais publicizados 1 .

Para atingir a dinâmica do capital que opera no caso da saúde, é preciso que se reorganize o trabalho do médico e dos outros profissionais, atuando nos seus processos decisórios, os quais ocorrem no ato mesmo da produção de saúde. Estes "novos" fazeres e práticas, necessitam tornarem-se concretos e materializaremse como "tecnologias de trabalho", usadas para produzir saúde 4 . Os processos de trabalho concretos, vivenciados nos serviços de saúde, são focos de atenção especial para os processos de gestão da mudança e existem "efeitos" do processo de trabalho, que se expressam no dia-adia dos serviços e, que devem ser "olhados" como lugares estratégicos-alvo para operações 
que podem disparar potencializações vitais, na direção de novos processos de produção de saúde 4 . Os "efeitos" do processo de produção do cuidado e suas tensões constitutivas, segundo Merhy 4, marcam os grandes temas contemporâneos dos debates sobre as práticas de gestão, no terreno dos serviços de saúde, tanto para os que visam a arranjos institucionais que permitam a estabilização de certos modelos de atenção, quanto para os que apostam na mudança destes. Desse modo, em qualquer uma destas direções, conservar ou mudar, existe a necessidade de se criar estratégias de ação gerencial para 4: impactar os exercícios privados dos profissionais, tornando-os mais controlados, produzindo com isso serviços mais centrados ou descentrados das óticas corporativas; atuar sobre as disputas que ocorrem quotidianamente, procurando impor controle sobre as mesmas e impor certos interesses particulares de alguns, como sendo universais.

Assim, para remodelar a assistência à saúde dentro da estratégia do PSF, deve-se modificar os processos de trabalho em curso; entende-se que a implantação do PSF, por si só, não significa que o modelo assistencial seja modificado, isso vai depender da forma de se conseguir reciclar a maneira de se produzir o cuidado em saúde.

Para que essas potencialidades para a construção do "novo" sejam capturadas, faz-se necessário a implementação de processos de autogestão do trabalho, que possam quotidianamente informar as disputas que se estabelecem no interior desse processo de trabalho 4 .

Merhy 4 defende que, uma análise das interfaces entre os sujeitos instituídos, seus métodos de ação e o modo como estes se interseccionam, permite realizar uma nova compreensão da tecnologia gerencial em saúde, tomando-se como eixo norteador o trabalho vivo em ato. Esse autor aposta na possibilidade de se constituir tecnologias de gestão do trabalho, que permitam identificar ruídos e quebras ocorridos nos processos de trabalho, que sejam fontes potenciais para a abertura de linhas de fuga aos processos de trabalho instituídos. $\mathrm{Pa}-$ ra esse autor, essas tecnologias de gestão do trabalho consistem no uso de instrumentos analisadores e auto-analíticos, como tecnologias potentes para propiciar avaliações do trabalho desenvolvido nos serviços de saúde.

A idéia de "instrumentos analisadores" se baseia no conceito de "analisador" proposto por Baremblit 5, trazido da psicanálise e utilizado na análise institucional. Para a psicanálise, um "analisador" é um fenômeno resultante de uma combinação, de uma mistura, da arti- culação de uma transição ou de uma transação entre as instâncias mentais, que têm como característica exprimir a problemática de um sujeito, manifestá-la e denunciá-la.

O "fluxograma analisador" se constitui num instrumento de análise, que interroga os "para que", os "que" e os "como" dos processos de trabalho, e ao mesmo tempo revela a maneira de governá-lo 4 . A idéia de se operar com instrumentos de natureza analítica apóia-se na proposta de que a construção de tecnologias que operem com processos auto-analíticos e autogestivos, articuladas às finalidades dos serviços de saúde, podem ser instrumentos potentes na viabilização do SUS e na viabilização da estratégia do PSF.

A questão norteadora deste estudo foi testar junto aos profissionais de saúde o "fluxograma analisador", mediante a verificação dos conteúdos analíticos por ele elaborados, ao visualizarem o processo de trabalho mapeado pelo "fluxograma analisador". Pretendia-se verificar se os profissionais conseguiam identificarse com aquele processo de trabalho desenhado, e a partir disso analisar os problemas e os pontos positivos do mesmo, terminando por elaborar propostas para superação dos problemas.

Assim, a finalidade deste texto é abrir uma reflexão sobre os processos auto-analíticos, ocorridos no interior de uma equipe de saúde da família, disparados a partir da apresentação do "fluxograma analisador", e com isso "propor" o uso desse instrumento como uma tecnologia de autogestão do trabalho.

Este estudo foi buscar as bases teóricas para sua realização nas concepções de processo de trabalho. Segundo Marx (1987, apud Merhy 4), o trabalho é compreendido como uma práxis, que expõe a relação homem/mundo, em um processo de mútua produção, concluindo com base nisso que, o trabalho produz o homem, mesmo que este seja fonte daquele e que, de modo virtual, seja o lugar da criação e o momento da existência e expressão do trabalho vivo em saúde.

A experiência Taylorista nos mostra que as organizações capitalistas sempre tiveram de conviver com a existência de um certo autogoverno do trabalhador no processo de trabalho, e que "aprenderam" a domesticá-lo e otimizálo para os processos da instituição.

O trabalho em saúde, entretanto, tem uma dinâmica muito peculiar, que faz com que o mesmo esteja sempre em estruturação, dentro de um quadro incerto, sobre o que é o padrão de seu produto final. Num centro de saúde, diferentemente de uma fábrica, não é possível obter estratégias organizacionais, plenamente 
competentes, que consigam "capturar" o trabalho vivo. A "captura" total do autogoverno dos trabalhadores, nas práticas de saúde, não só é muito difícil, como impossível, pela natureza tecnológica deste trabalho 4 .

Frente ao exposto, o objetivo colocado para este trabalho foi discutir e analisar, com profissionais das equipes de PSF, o uso do "fluxograma analisador" como um instrumento de autoanálise e de autogestão do processo de trabalho em saúde.

\section{Trajetória metodológica}

Entende-se que, para se atingir os objetivos de uma pesquisa é fundamental a escolha de procedimentos metodológicos que viabilizem uma resposta às questões que o tema suscita, dessa forma, a presente pesquisa opta por uma abordagem qualitativa, pois esse tipo de abordagem permite incorporar a questão do significado e da intencionalidade como inerentes aos atos, às relações e às estruturas sociais 6 .

O recurso metodológico para a apreensão do real a ser utilizado é o depoimento dos profissionais da equipe de PSF sobre o mapeamento de seu trabalho pelo "fluxograma analisador", obtido por meio da dinâmica de grupo focal.

A pesquisa foi realizada em uma unidade de saúde, localizada no Distrito Sanitário Escola Butantã. Essa unidade de saúde contava com cinco equipes de PSF. Foram sujeitos da pesquisa: duas enfermeiras, dois médicos, quatro agentes comunitários de saúde e duas auxiliares de enfermagem que atuam nas equipes do PSF dessa unidade, que puderam e se dispuseram a participar da pesquisa. Esses profissionais não trabalham, necessariamente, na mesma equipe.

Os dados foram coletados após o projeto ter sido submetido ao Comitê de Ética da Prefeitura Municipal de São Paulo, atendendo assim à resolução de número 196/96 que trata de pesquisas envolvendo seres humanos. Os profissionais do PSF que consentiram voluntariamente em colaborar com o estudo assinaram o termo de consentimento livre e esclarecido.

A coleta de dados foi realizada utilizandose a técnica do grupo focal. O grupo focal é uma técnica de entrevista em grupo, muito utilizada para obterem-se dados relativos a sentimentos e opiniões de pequenos grupos acerca de determinados problemas, e também para desencadear conhecimentos, atitudes e práticas de alguns grupos sociais 7 .

Em data pré-agendada os profissionais acima descritos participaram de uma dinâmica de grupo que seguiu as seguintes etapas:
(1) etapa de apresentação e introdução ao trabalho em grupo: neste momento houve a apresentação dos profissionais e dos coordenadores da dinâmica de grupo, bem como a apresentação dos objetivos do trabalho em grupo e da pesquisa;

(2) etapa de desenvolvimento do trabalho de grupo: neste momento tem início o núcleo central do trabalho do grupo, onde se realiza a apresentação, em cartazes, de dois "fluxogramas analisadores" do processo de trabalho de "acolhimento" e a explicação do que significa cada figura presente no fluxograma. O "fluxograma analisador", utilizado para discussão, foi construído na pesquisa As Potencialidades da Tecnologia de Acolhimento para o Controle das Doenças Transmissíveis no Programa Saúde da Família 8. A ação de "acolhimento" foi escolhida porque é uma atividade que todos os trabalhadores de saúde no PSF realizam;

(3) etapa de análise e discussão do fluxograma: nesta etapa estimula-se os profissionais participantes do grupo a emitirem suas considerações sobre o processo de trabalho desenhado no fluxograma exposto. Os depoimentos foram gravados, a dinâmica do grupo foi registrada e as fitas transcritas.

Os discursos obtidos, como resultado da dinâmica do grupo focal, foram analisados utilizando-se a técnica de discurso do sujeito coletivo ${ }^{9}$. O discurso do sujeito coletivo constitui uma técnica de organização de dados discursivos em pesquisa qualitativa que permite resgatar o estoque de representações sobre um determinado tema em um dado universo. A matéria-prima a ser trabalhada pelo discurso do sujeito coletivo é o pensar expresso de forma discursiva de um conjunto de sujeitos sobre um certo assunto. Os discursos são submetidos a uma análise de conteúdo que se inicia pela decomposição desses nas principais ancoragens ou idéias centrais presentes em cada um individualmente e em todos reunidos, seguindo-se a uma síntese que visa à reconstituição discursiva da representação social 9 .

As figuras metodológicas constitutivas da proposta do discurso do sujeito coletivo incluem: expressão-chave, idéia central, ancoragem e discurso do sujeito coletivo. Expressãochave é a transcrição literal de trechos ou segmentos, contínuos ou descontínuos, do discurso que permitem o resgate do essencial do conteúdo discursivo; idéia central é um nome ou expressão lingüística que traduz o essencial do conteúdo discursivo explicitado pelos sujeitos; ancoragem abarca os pressupostos, as teorias, os conceitos, as hipóteses e as ideologias existentes na sociedade e na cultura, e que inter- 
nalizados no indivíduo, usualmente, alicerçam um discurso.

O discurso do sujeito coletivo é a reunião em um discurso-síntese das expressões-chave que manifestam a mesma idéia central ou ancoragem. Os indivíduos se dissolvem e se incorporam num ou em vários discursos coletivos que expressam a representação social acerca de um determinado tema da coletividade a qual pertencem. O discurso do sujeito coletivo configura uma "coletividade discursiva", cujo conteúdo compõe-se pelo que é falado por um sujeito individual e pelo que seu "companheiro de coletividade" atualiza por ele. Os passos até a síntese nos discursos do sujeito coletivo incluem 9: (a) leitura do conjunto dos depoimentos coletados nas entrevistas; (b) leitura da resposta a cada pergunta em particular, marcando as expressões-chave selecionadas; (c) identificação das idéias centrais de cada resposta; (d) análise de todas as expressões-chave e idéias centrais, agrupando as semelhantes em conjuntos homogêneos; (e) identificação e nomeação da idéia central do conjunto homogêneo, que será uma síntese das idéias centrais de cada discurso; (f) construção dos discursos do sujeito coletivo de cada quadro obtido na etapa anterior; (g) atribuição de um nome ou identificação para cada um dos discursos do sujeito coletivo.

\section{Resultados}

Como propõe a técnica do discurso do sujeito coletivo, as falas dos sujeitos foram organizadas segundo a idéia central que as mesmas trazem e os temas que constituem estas idéias centrais.

Neste estudo encontramos nos registros das discussões do grupo a existência de três idéias centrais, quais foram: (1) o acolhimento é um processo de trabalho que integra o Programa Saúde da Família devendo-se, no entanto, estar atento à forma de sua realização; (2) o acolhimento determina como será a porta de entrada da unidade de saúde; (3) o fluxograma analisador é um instrumento potente para avaliação do processo de trabalho.
Idéia central I: o acolhimento é um processo de trabalho que integra o Programa Saúde da Família devendo-se, no entanto, estar atento à forma de sua realização

\section{- Tema A: processo de trabalho} de acolhimento é resolutivo e acolhedor

Discurso do sujeito coletivo: “(...) [há] acolhimento onde existe uma necessidade de entender o que a pessoa veio procurar na unidade, perceber o que ela quer e resolver na unidade.(...) Você não pode falar que a pessoa só veio para conversar (...) [muitas vezes] aquela queixa de dor e de tontura com uma conversa a gente esclareceu e viu que não era [central], (...) só que a pessoa não colocou isso na [sua] fala quando descreveu seu problema. O acolhimento em si é terapêutico, [a pessoa] precisa falar com alguém e só isso ajuda a passar a dor [pela qual] ela foi em busca de uma vaga médica [e ao final] a pessoa admitiu que estava se sentindo melhor e que ela precisava falar porque não tem com quem falar".

\section{- Tema B: processo de trabalho não é resolutivo}

Discurso do sujeito coletivo: “(...) ela [a paciente] estava também com [uma] queixa clínica e também não foi encaminhada para [nenhum] lugar. (...) ela [profissional] não deu resolutividade, não deu encaminhamento [e tentou pelo que aparece no tom do quadro meio pejorativo] 'ai meu Deus do céu ela só quer conversar' então não tem uma resolubilidade a partir da conversa, parou ali. [Uma outra questão importante] (...) mais até do que se preocupar com o ar do paciente naquele momento, a gente tem que se preocupar com os rótulos que impedem a gente de ver a realidade, pode até ser que como eu estou no grupo [equipe de PSF] eu já conhecesse a história da pessoa (...) na hora que eu falo, uma pessoa que procura atendimento, já é diferente, é uma pessoa que busca os meus cuidados (...) o que impacta é eu saber que é uma pessoa que busca o meu atendimento é é uma pessoa que não sabe o que tem (...) então eu fico meia hora ali cutucando até identificar que ela tem tontura e perna machucada, uma queixa biológica e aí qual foi a terminalidade, qual foi a intervenção que ele [profissional] fez nessa queixa biológica? Nenhuma (...) dependendo da situação, do local e da demanda (...) se eu tenho 16 vagas e 30 pacientes é bom que eu atenda logo, senão, quer dizer, dependendo de como eu me organizar, se eu começo atendendo e fico trinta minutos com uma pessoa, como é que eu vou dar conta do restante (...)". 
- Tema C: processo de trabalho não articula social e biológico

Discurso do sujeito coletivo: “(...) se o trabalhador que atendeu tivesse falado dessa coisa para além [do biológico], por exemplo, como já falaram a paciente não comeu. Se comeu, é só mudar o enfoque. (...) quando ela atende só fala assim: chegou uma paciente psiquiátrica, sentou lá, começou a falar e aí eu fui perguntando, mas a paciente tinha uma aceleração de pensamento, não conseguia responder, até que ela me disse que tinha tontura e estava com a perna machucada (...) eu não sei se ela mora na favela e tal (...) a pessoa [o profissional] não faz essa articulação. [Num] Atendimento, o que acontece, eu vou [identificar] uma série de coisas que de verdade eu não tenho como resolver, eu posso até propor soluções, quem de nós no acolhimento já não teve que ouvir as angústias de uma pessoa, aí talvez o que eu precise fazer é saber [como intervir], então eu vou enrolando, isso denuncia um ruído aí, eu acredito numa coisa e acabo produzindo outra. (...) chega uma paciente com uma dor no peito, quando ela começa a falar e você não vai de imediato na dor, você deixa ela falar e ela fala trinta minutos com você, de toda uma situação de problema que ela tá enfrentando na casa dela, no relacionamento com o marido e com os filhos; ao diagnosticar a dor no peito eu sei que é de fundo nervoso (...) a gente [profissionais] tem que aprender a olhar as questões individuais e coletivas (...)”.

- Tema D: processo de trabalho é resolutivo se o profissional é "treinado" para triagem

Discurso do sujeito coletivo: “(...) se uma conduta [clínica] é correta ou não depende da capacitação do profissional. (...) no caso aqui o profissional foi perguntando e chegou ao diagnóstico: tontura e perna machucada. (...) se eu tenho uma pessoa que procura atendimento [na unidade básica de saúde] e eu vou ter que atender, o que eu estou conseguindo produzir no momento é um agendamento de exame, uma conduta para resolver, eu estou conseguindo ouvir até entender que ela tem uma tontura (...) uma determinada queixa (...). Outra [questão importante] é essa questão de limite [da prática clínica da enfermagem], e se vocês lembrarem bem foi por isso que surgiu a questão do protocolo que ameniza um pouco a questão da clínica. (...) [uma pessoa que esperou na fila] não $t i$ nha nada visível, porque a pessoa [profissional] não ia demorar trinta minutos [para atender] se estivesse olhando uma perna machucada ou alguma dificuldade de deambulação".
Num primeiro momento da análise, os profissionais olham para o processo de trabalho descrito e passam a avaliá-lo como positivo ou negativo, como adequado ou inadequado ou, como querem os sujeitos, como resolutivo ou não. A seguir, chegam mesmo a identificar questões que tornam esse processo de trabalho mais ou menos resolutivo, tais como, abordar o biológico e não o social; o preparo do profissional de saúde para a atividade de triagem, confundida como a centralidade do acolhimento. Para os termos da pesquisa, o surgimento desses temas nas discussões do grupo, atinge o objetivo de identificar se o "fluxograma analisador" é capaz de desencadear, nos profissionais de saúde, um processo de auto-análise do seu trabalho.

Idéia central 2: o acolhimento

determina como será a porta de entrada da unidade de saúde

\section{- Tema A: é preciso ter um motivo biológico} para poder entrar no serviço de saúde

Discurso do sujeito coletivo: “(...) aquilo serviu de desculpa, uma justificativa para a pessoa que quer 'conversar' [e vai] (...) até a unidade (...) [de fato] ela não estava com tontura, essa foi a justificativa, ela não comeu, estava com problema, tem uma perna machucada (...) [essa é a razão real]".

\section{- Tema B: acolher é mais que triagem}

Discurso do sujeito coletivo: “(...) olha tem uma pessoa por trás dela (...) ela é uma pessoa com má história de vida que procura, então eu acho que isso já mostra. (...) eu tenho sentido que o acolhimento não é acolhimento, na verdade ele está identificado como PA, como triagem, muito mais centrado nas queixas clínicas. [porque o acolhimento] Tem que levar em consideração [que o usuário] (...) está [inserido] no meio [social], [o profissional] que escutou durante trinta minutos, porque [ao] escutar durante trinta minutos você escuta muita coisa, não [foi] só (...) triagem, o outro não escutou nada, só fez o diagnóstico, essa [o primeiro] pessoa escutou, essa pessoa acolheu".

\section{- Tema C: acolher é menos que triagem}

Discurso do sujeito coletivo: “(...) ouvir [durante] trinta minutos e não mudar o resultado, não sabemos [se esse foi o resultado do acolhimento] porque não tem um encaminhamento. (...) a pessoa [profissional] demorou trinta minutos para chegar [no diagnóstico] de tontura e perna 
machucada e não sabe o que fazer com o resto. $E$ (...) termina no encaminhamento para consulta ou só com uma conversa".

Nesse bloco de considerações, suscitadas pelo "fluxograma analisador", o grupo passa a questionar qual é a centralidade (a finalidade) do processo de trabalho em análise, questionando o fato de que, se ele for a porta de entrada do PSF, tem de operar com uma lógica diferente da biologicista e médico-centrada. Num segundo momento, o grupo identifica que os instrumentos de trabalho utilizados por eles, para operar o acolhimento (saberes e técnicas), não são suficientes para realizar a finalidade proposta para o processo de trabalho de acolhimento.

Idéia central 3: o "fluxograma analisador" é um instrumento potente para avaliação do processo de trabalho - Tema A: o "fluxograma analisador"
denuncia o processo de trabalho

Discurso do sujeito coletivo: “(...) ele [o fluxograma] deixa claro a dificuldade que a gente [profissionais] tem para aplicar tudo o que vocês colocaram no acolhimento [teoria] e transformar isso em trabalho (...) esse fluxograma denuncia na verdade, o ponto falho do dia-adia.(...) a gente fala tanto em acolhimento mas na hora que a gente vai fazer acolhimento, a gente volta para a queixa e repete o processo de trabalho [clínico e biomédico] de novo".

\section{- Tema B: o "fluxograma analisador" evidencia os instrumentos do processo de trabalho}

Discurso do sujeito coletivo: “(...) conversar, é pouca coisa? Isso é um instrumento de intervenção, a comunicação é um instrumento de intervenção [em saúde] (...) o que a gente discute quando olha [o processo de trabalho] é (...) que instrumento a (...) pessoa utilizou, em nenhum momento ela foi buscar o saber relacional ou um saber na psiquiatria, ou na saúde mental, ela operou com o saber clínico. (...) quando a gente diz mudar (...) a concepção é adotar outros saberes na nossa prática, é incorporar outros saberes além do clínico. (...) se eu quero transformar o acolhimento em algo eficiente (...) não (...) numa sala específica, numa caixinha com horários e regras pré-determinadas, (...) [eu tenho de mudar] o seu momento de organização também da recepção (...) [tem de ser] uma atitude de acolhimento. (...) o PSF tem a potencialidade de ir para o domicílio, fazer uma busca ativa ou fazer uma supervisão dessa pessoa (...) talvez fosse legal que um agente comunitário fosse até a casa para ver como a pessoa está".

Nessa idéia central podemos identificar que os profissionais acolhem o "fluxograma analisador" como um instrumento que possibilita a auto-análise e autogestão do processo de trabalho, uma vez que ao identificarem pontos críticos, discutem as possíveis soluções para os mesmos.

Os discursos do sujeito coletivo acima nos indicam que, ao submeter o processo de trabalho de acolhimento para análise dos profissionais de saúde, que ao mesmo tempo são os "agentes" desse processo de trabalho, desencadeamos uma reação que vai desde identificar como esse processo de trabalho se articula, até identificar quais os meios e instrumentos que esse processo utiliza para se concretizar e as formas de superar as dificuldades do mesmo.

\section{Considerações finais}

O PSF, enquanto uma estratégia técnico-política do Ministério da Saúde, para a implementação do SUS, constitui-se em uma estratégia para reorganizar a atenção básica, implementando uma mudança no enfoque da assistência ao processo saúde-doença; priorizando as ações de proteção e promoção à saúde dos indivíduos e da família, tanto dos adultos quanto das crianças, sadios ou doentes, de forma integral e contínua. A implementação do PSF implica a interação com a comunidade, especialmente aquela da área de adscrição de cada equipe, visando a construir, de forma participativa, práticas e estratégias mais eficazes de enfrentamentos aos problemas e necessidades de saúde. Isso exige dos trabalhadores e profissionais de saúde que atuam no PSF, a incorporação de contínuas discussões acerca do seu processo de trabalho e da relação que travam com os usuários dos serviços de saúde, pois no encontro entre trabalhador e usuário operam processos tecnológicos (trabalho vivo em ato) que visam à produção de relações de escutas e responsabilizações, que se articulam com a constituição de vínculos e dos compromissos em projetos de intervenção 4 .

Os resultados encontrados mostraram que o "fluxograma analisador" é um instrumento capaz de captar a estrutura do processo de trabalho desenvolvido, evidenciando as lógicas presentes nos mesmos, bem como os saberes e práticas predominantes e, o mais importante, sendo capaz de propiciar aos profissionais de 
saúde que eles, por si só, visualizem como seu processo de trabalho se conforma e busquem formas de remodelá-lo.

A visualização do processo de trabalho, por intermédio do "fluxograma analisador", possibilitou que os profissionais, individualmente e em grupo, discutissem o trabalho que realizam e o trabalho que os outros membros da equipe fazem, possibilitou, também, que cada profissional visualizasse a finalidade da sua ação, identificando que, embora a ação de acolhimento estivesse vinculada a uma proposta de mudança do modelo, na prática, a ação de cada um estava reiterando o modelo biologicista e médico-centrado.

O uso do "fluxograma analisador" possibilitou, também, que os profissionais realizassem uma reflexão sobre a sua prática, reflexão esta que tem potencialidade para ajudar na mudança da referência epistemológica do sujeito, despertando no mesmo a necessidade de capacitação para um agir diferente.

Ao discutir o processo de trabalho mapeado pelo "fluxograma analisador", o profissional de saúde foi capaz de identificar a necessidade de rever os instrumentos de trabalho que vem utilizando, para realizar suas práticas de saúde, conseguindo entender a importância do planejamento participativo para o trabalho em equipe.

\section{Resumo}

Para remodelar a assistência à saúde dentro da estratégia do Programa Saúde da Família (PSF) deve-se modificar os processos de trabalho em curso. Os processos de trabalho vivenciados nos serviços de saúde são focos de atenção especial para os processos de gestão da mudança e compõem os grandes temas contemporâneos dos debates sobre as práticas de gestão em saúde. O objetivo deste estudo foi discutir e analisar com os profissionais do PSF, a utilização do "fluxograma analisador" como instrumento de auto-análise e autogestão do trabalho. Os dados foram coletados por meio da dinâmica de grupo focal e analisados segundo a técnica de Discurso do Sujeito Coletivo. Os resultados mostraram que o "fluxograma analisador" $e$ um instrumento potente para impactar os exercícios privados dos profissionais, tornando-os mais controlados e produzindo com isso serviços mais descentrados da lógica medicocêntrica; é um instrumento capaz de atuar sobre as disputas que ocorrem entre os diferentes profissionais dos serviços de saúde, procurando impor um certo controle sobre estas.

Programa Saúde da Família; Prestação de Cuidados de Saúde; Pessoal de Saúde
O "fluxograma analisador" é, também, potente para identificar as disputas que ocorrem no interior dos processos de trabalho e os interesses entre os diferentes profissionais, que disputam o poder de dar direcionalidade ao trabalho da equipe de saúde, revelando que a referência clínica ainda é a base sobre a qual se inscreve a maioria dos processos de trabalho em saúde.

O "fluxograma analisador" permitiu que os profissionais de saúde pudessem identificar as possíveis falhas, ou seja, o "o que" e o "como" do processo de trabalho, que precisam ser modificados. Esta questão é muito importante, pois quando o sujeito por si só identifica qual é a mudança que precisa ser feita, estamos identificando a expressão do trabalho vivo, em ato, criador, capaz de subsumir o trabalho morto e dar nova direcionalidade para o trabalho em saúde. O trabalho em saúde por estar sempre em estruturação, dentro de um quadro incerto sobre o que é o padrão de seu produto final, necessita de estratégias organizacionais competentes para "capturar" o autogoverno dos trabalhadores no sentido de torná-lo capaz de viabilizar o SUS.

Enfim, pode-se concluir com este estudo que o fluxograma é um instrumento potente para operar na direção de se produzir serviços e profissionais de saúde mais responsabilizados e criativos com seu processo de trabalho.

\section{Colaboradores}

T. A. V. Barboza realizou a redação da primeira versão do artigo. L. A. Fracolli foi a responsável pelo desenvolvimento das correções sugeridas pela revista e pela redação da segunda versão do artigo. 


\section{Referências}

1. Franco TB, Merhy EE. PSF: contradições de um programa destinado à mudança do modelo assistencial. In: Mehy EE, Magalhães Jr. HM, Rimoli J, Franco TB, Bueno WS, organizadores. O trabalho em saúde: olhando e experienciando o SUS no cotidiano. São Paulo: Editora Hucitec; 2003. p. 55124.

2. Merhy EE. A perda da dimensão cuidadora na produção da saúde: uma discussão do modelo assistencial e da intervenção no seu modo de trabalhar a assistência. In: Merhy EE, Campos CR, Malta DC, organizadores. Sistema único de saúde em Belo Horizonte: reescrevendo o público. São Paulo: Xamã; 1998. p. 103-20.

3. Chiesa AM, Batista KBC. Desafios da implantação do PSF em uma grande metrópole: reflexões acerca da experiência de São Paulo. Mundo Saúde 2004; 28:42-8.

4. Merhy EE, Onocko R, organizadores. Agir em saúde: um desafio para o público. São Paulo: Editora Hucitec; 1997.
5. Baremblitt GF. Compêndio de análise institucional e outras correntes: teoria e prática. Rio de Janeiro: Rosa dos Tempos; 1996.

6. Minayo MCS. O desafio do conhecimento: pesquisa qualitativa em saúde. 6a Ed. São Paulo: Editora Hucitec/Rio de Janeiro: ABRASCO; 1999.

7. Morgan DL. Focus groups as qualitative research. London: Sage Publications; 1988.

8. Alves CL, Fracolli LA. As potencialidades da tecnologia de acolhimento para o controle das doenças transmissíveis no Programa Saúde da Família. In: 9o Simpósio Internacional de Iniciação Científica da Universidade de São Paulo. Ribeirão Preto: Pró-reitoria de Pesquisa, Universidade de São Paulo; 2001.

9. Lefrève F; Lefrève AMC, Teixeira JJV. O discurso do sujeito coletivo: uma nova abordagem metodológica na pesquisa qualitativa. Caxias do Sul: EDUCS; 2000.

Recebido em 08/Jun/2004

Versão final reapresentada em 03/Nov/2004 Aprovado em 03/Fev/2005 